\title{
Peristeen anal irrigation as a substitute for the MACE procedure in children who are in need of reconstructive bladder surgery
}

\author{
Husain Alenezi, MD; Hamdan Alhazmi, MD; Mahmoud Trbay, MD; Amna Khattab; Khalid Fouda Neel, MD
}

King Khalid University Hospital, King Saud University, Riyadh, Saudi Arabia

Cite as: Can Urol Assoc J 2014;8(1-2):e12-5. http://dx.doi.org/10.5489/cuaj.1263

Published online January 14, 2014.

\section{Abstract}

Introduction: We evaluate the efficacy of the Peristeen (Coloplast A/S, Kokkedal, Denmark) transanal irrigation (TAI) system, as a stool cleansing mechanism, to gain stool continence in children who need reconstructive bladder surgery and have fecal incontinence. Methods: We prospectively evaluated children with neuropathic bladder and bowel dysfunction who were intended for reconstructive bladder surgery and the Malone antegrade continence enema (MACE) procedure. All patients were started on the Peristeen TAI system at least 3 months before surgery to assess their response. Each patient's bowel function, frequency of using the system, satisfaction (and that of their parents) and diaper independency were evaluated before and after reconstructive surgery.

Results: We included 18 patients ( 11 female, 7 male) who were evaluated from April 2006 to the present. The mean age of the group was 7.6 years (range: $4-15)$. Fifteen patients $(83.3 \%)$ showed complete dryness from stools. Of the 15 patients, 8 (53.3\%) were able to be diaper-free, while 6 continued wearing diapers due to fear of soiling and 1 due to urinary incontinence. The patients underwent reconstructive bladder surgery and continued to use the Peristeen TAl system with the same results postoperatively. The main limitation of this study is the small number of patients included, although this is a very specific patient group.

Conclusion: Our initial results suggest that the Peristeen TAI system is a successful conservative substitute for the MACE procedure in children who require reconstructive bladder surgery.

\section{Introduction}

Children with neuropathic bladder due to myelomeningocele or other spinal cord lesions commonly have accompanying neuropathic bowel dysfunction (NBD). ${ }^{1,2}$ Neuropathic bowel dysfunction can manifest as chronic constipation, fecal incontinence or both. ${ }^{3-5}$ Neuropathic bowel dysfunction has a significant negative impact on a patient's quality of life and functional capacity. ${ }^{6}$

The management of neuropathic bowel dysfunction starts with conservative measures, including diet modification, oral laxatives, rectal enemas, manual evacuation or various combinations of these measures. ${ }^{7,8}$ Unfortunately, many patients fail to adequately respond to conservative bowel management. ${ }^{9}$

Since Malone and colleagues presented a preliminary report of an antegrade colonic enema (Malone antegrade continence enema [MACE]) procedure in $1990,{ }^{10}$ it has gained wide acceptance by urologists as a successful treatment for intractable neuropathic bowel dysfunction. ${ }^{11-16}$ However, the MACE procedure is an invasive operation with a relatively high incidence of complications. ${ }^{12-16}$

In recent years, transanal irrigation (TAI) has become a popular option in the management of NBD due to its successful results and acceptable safety profile. ${ }^{17-23}$ TAI has been suggested as a first-line therapy for children with neuropathic bowel dysfunction who do not respond to conservative medical therapy. ${ }^{9}$ Moreover, TAl constitutes an integral part of the total endoscopic and anal irrigation management (TEAM) approach in children with noncompliant NB. ${ }^{17}$

The aim of this study was to evaluate the efficacy of TAI as an alternative to the MACE procedure in children with neuropathic bladder and neuropathic bowel dysfunction who need reconstructive bladder surgery.

\section{Methods}

After approval from the internal review board, we conducted a prospective evaluation of children with neuropathic bladder and neuropathic bowel dysfunction (constipation and fecal incontinence) who failed to benefit from conservative medical management. Patients who were intended for 


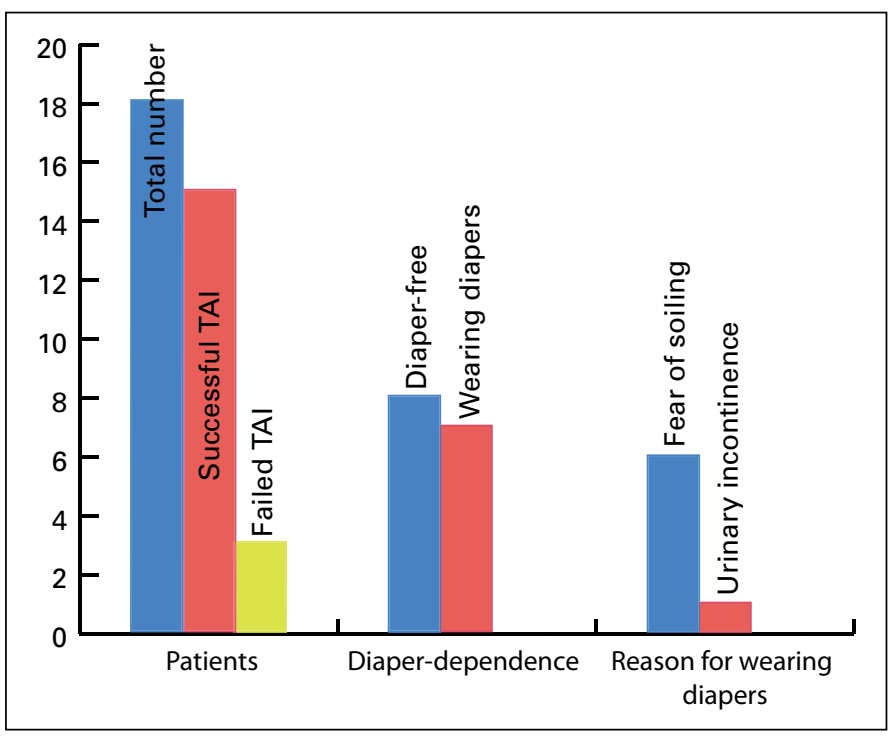

Fig. 1. Transanal irrigation results.

reconstructive bladder surgery and MACE procedure were included in this study.

All patients were started on the Peristeen (Coloplast A/S, Kokkedal, Denmark) TAl system at least 3 months prior to the date of planned surgery. The patients and their parents were interviewed by a specialized urotherapist for a verbal and visual demonstration of the TAI technique and its goals. At the end of the interview, the patients and their parents were supplied with a simplified brochure about the TAI system, along with a contact number for any further questions. The patients and their parents were instructed to perform the TAI 3 times per week using $50 \mathrm{~mL}$ of tap water per kilogram of body weight during each use. Further instructions were also given related to adjustments in the frequency of TAI and water volume according to the response and based on symptoms, such as abdominal pain. So if patients achieve good response (dry at all times), then the frequency of using TAI can be reduced to twice per week. While in the case of mild abdominal pain, the water volume irrigation should be reduced gradually by $5 \mathrm{~mL}$ per kilogram with each use until pain disappears. All patients and their parents were advised to avoid dehydration, maintain good hygiene and immediately report the rare occurrence of severe abdominal pain and fever.

The patients were seen in the clinic at 6 weeks before surgery, after inclusion in the study.

The primary outcome measure of this study was response to TAI. We defined successful response as complete dryness from stool soiling with minimal or no constipation. Secondary outcome measures were diaper-independency, patient and parent satisfaction and the weekly frequency of TAI use. In the second clinic visit, the patients with successful responses and good satisfaction using TAl were offered bladder reconstructive surgery (augmentation ileocystoplas- ty) with continuation of TAI postoperatively. Patients with poor responses to TAI were offered bladder reconstructive surgery (augmentation ileocystoplasty) and MACE procedure. The patients returned for regular follow-up appointments after surgery, and overall response was evaluated.

\section{Results}

In total, 18 patients ( 11 female, 7 male), were included in the study. The mean age of the group was 7.61 years (range: 4 to 15). Postoperative follow-up ranged from 4 to 86 months (mean: 49.6). The mean postoperative follow-up period for TAl patients was 43.4 months.

Fifteen patients had successful responses to TAI at preoperative visit. The frequency of TAI was once per week in 1 patient, twice per week in 10 patients and 3 times per week in 4 patients. Successfully responding patients and their parents were satisfied with the results from TAI and were comfortable with its use, with the exception of 1 patient who had a patulous anus and had difficulty in maintaining the TAl system in the rectum during irrigation. Four patients had transient mild abdominal discomfort, which resolved after reducing the amount of irrigation and did not prevent them from continuing TAI. All responders underwent augmentation ileocystoplasty alone, and they continued to use TAI postoperatively with the same level of response and satisfaction. Postoperatively, 8 of the 15 patients were able to shift from wearing diapers to regular underwear. The remaining 7 patients were still wearing diapers either due to the fear of soiling (6 patients) or persistent urinary incontinence (1 patient). Children who were afraid of soiling wore diapers mostly while going outside or during school time.

The cause of the poor response to TAI in the other 3 patients was mainly due to non-compliance. Those patients and their parents were not comfortable using the TAl system and were not satisfied with its results. Two of the 3 patients underwent augmentation ileocystoplasty with the MACE procedure. The first patient was a 6-year-old boy who had good response to the MACE procedure, with resolution of stool soiling in the postoperative follow-up. The second patient was a 12-year-old girl with intractable neuropathic bowel dysfunction and poor compliance to all treatment measures, so extensive preoperative counselling of the patient and her parents was undertaken before proceeding with augmentation ileocystoplasty and MACE. This patient had poor response to MACE, and she was referred to a colorectal surgeon, who advised terminal ileostomy as a last resort for her intractable symptoms. The third patient was a 15-yearold boy. This patient refused all surgical treatment options for neuropathic bowel dysfunction to avoid catheterizable stoma, so he underwent augmentation ileocystoplasty alone and clean intermittent catheterization per urethra. He was placed back on extensive conservative bowel management 


\begin{tabular}{|c|c|c|c|c|}
\hline Author & Year/country & No. patients & Success rate & Complications \\
\hline Tiryaki et al. ${ }^{12}$ & 2010/Turkey & 32 & $59 \%$ & $\begin{array}{c}\text { Stenosis } 14 / 32 \\
\text { Perforation } 2 / 32 \\
\text { Leakage } 5 / 32\end{array}$ \\
\hline Meurette et al. ${ }^{13}$ & 2010/France & 25 & $52 \%$ & Not available \\
\hline Bani-Hani et al. ${ }^{14}$ & 2008/United States & 236 & $94 \%$ & $\begin{array}{c}\text { Stenosis } 14 \% \\
\text { Leakage } 0.9 \% \\
\text { Surgical revision } 17 \%\end{array}$ \\
\hline Yerkes et al. ${ }^{15}$ & 2003/ United States & 65 & $77 \%$ & Not available \\
\hline Wedderburn et al. ${ }^{16}$ & 2001/United Kingdom & $\begin{array}{l}46 \text { with bladder } \\
\text { reconstruction }\end{array}$ & $76 \%$ & Stenosis $17 \%$ \\
\hline
\end{tabular}

with only mild response; eventually, he required insertion of a cecostomy tube for antegrade irrigation.

\section{Discussion}

Treatment of NBD in patients with myelomeningocele is an important step for improving the patients' quality of life. Unfortunately, patients with intractable neuropathic bowel dysfunction usually require more invasive and complicated procedures for their treatment.

The MACE procedure has been used widely by urologists with relatively high success rates. However, it is associated with a significant complication rate and requires surgical revision in nearly one-fifth of patients (Table 1). ${ }^{12-16}$ Therefore, Malone and colleagues stated that "all conservative measures must be tried first" before the MACE procedure. ${ }^{11}$

Published data have demonstrated that TAI is highly successful to treat patients with neuropathic bowel dysfunction who failed to benefit from conservative medical therapy. ${ }^{9,17-23}$ TAI was associated with an excellent safety margin, and the reported complications were mostly minor and related to catheter manipulation (Table 2). ${ }^{17-21}$
Forty-five pediatric patients using TAI were presented in the European Society for Pediatric Urology Annual Meeting in $2010 .{ }^{22}$ The success rate was $88.8 \%$ (defined as complete dryness from fecal soiling), and complications included catheter expulsion $(15.5 \%)$, leakage $(13.3 \%)$ and transient abdominal pain (8.8\%).

Therefore, TAI has a success rate comparable to the MACE procedure in treating intractable neuropathic bowel dysfunction, with decreased surgical morbidity and a better safety profile. In this study, $83.3 \%$ of patients were successfully managed by TAI as an alternative to MACE. This translated to a less complicated reconstructive procedure (i.e., only requiring urinary reconstruction, decreased operative time and most likely reduced postoperative complications). Matsuno and colleagues retrospectively compared 25 patients with spina bifida and fecal incontinence using either TAI or MACE. ${ }^{23}$ They found no difference in the achievement of fecal continence between the 2 groups and concluded that TAI is not inferior to MACE. Our prospective results support their recommendation in considering TAI prior to the introduction of MACE in children with spina bifida.

There are a few limitations to our study. The first is the small number of patients from a single centre, although this

Table 2. Outcome of transanal irrigation from different studies

\begin{tabular}{|c|c|c|c|c|}
\hline Author & Year/country & No. patients & Success rate & Complications \\
\hline Neel ${ }^{17}$ & 2010/Kingdom of Saudi Arabia & 10 (TEAM approach) & $100 \%$ & None (early experience) \\
\hline Pereira et al. ${ }^{9}$ & 2010/Spain & 35 & $100 \%$ & $\begin{array}{c}\text { Catheter expulsion } 17 \% \\
\text { Leakage of irrigation fluid } 26 \%\end{array}$ \\
\hline Christensen et al. ${ }^{18}$ & 2008/5 European countries & 62 & $88.7 \%$ & $\begin{array}{l}\text { Catheter expulsion } 8 \% \\
\text { Leakage } 30 \% \\
\text { Abdominal pain } 1.6 \% \\
\text { Still dependent } 40 \%\end{array}$ \\
\hline Ausili et al. ${ }^{21}$ & 2010/Italy & 60 (SCl patients) & $75 \%$ & $\begin{array}{c}\text { Catheter expulsion } 6.6 \% \\
\text { Dependence } 73.3 \%\end{array}$ \\
\hline Popolo et al. ${ }^{19}$ & 2008/ltaly & 32 (SCl patients) & $68 \%$ & $\begin{array}{c}\text { Catheter expulsion } 34 \% \\
\text { Leakage } 59 \% \\
\text { Still dependent } 25 \%\end{array}$ \\
\hline Trbay and Neel. ${ }^{22}$ & 2010/Kingdom of Saudi Arabia & 45 & $88.8 \%$ & $\begin{array}{c}\text { Catheter expulsion } 15.5 \% \\
\text { Leakage } 13.3 \% \\
\text { Abdominal pain } 8.8 \%\end{array}$ \\
\hline
\end{tabular}

TEAM: total endoscopic and anal irrigation management; SCl: spinal cord injury. 
is a selective group of patients, and we believe that further multicentre studies will show the same results and conclusion. The second limitation is the lack of an appropriate Arabic quality of life questionnaire for patient follow-up, which we will try to formulate in the near future.

\section{Conclusion}

Our initial results suggest that TAI is a successful conservative alternative to MACE in children with myelomeningocele and fecal incontinence who require bladder reconstructive surgery. TAI is an option that should be discussed with the patient's parents before proceeding to reconstructive surgery.

Competing interests: Dr. Alenezi, Dr. Alhazmi, Dr. Trbay, Ms. Khattab and Dr. Neel all declare no competing financial or personal interests.

This paper has been peer-reviewed.

\section{References}

1. Botto L, Moore CA, Khoury MJ, et al. Neural tube defects. N Engl J Med 1999;341:1509-19. http:// dx.doi.org/10.1056/NEJM199911113412006

2. Emmanuel AV, Chung EA, Kamm MA, et al. Relationship between gut-specific autonomic testing and bowel dysfunction in spinal cord injury patients. Spinal Cord 2009;47:623-7. http://dx.doi.org/10.1038/ sc.2009.14

3. Mattsson $\mathrm{S}$, Gladh $\mathrm{G}$. Enema for children with myelomeningocele and neurogenic bowel dysfunction. Acta Paediatr 2006;95:369-74. http://dx.doi.org/10.1080/08035250500437507

4. Krogh K, Mosdal C, Laurberg S. Gastrointestinal and segmental colonic transit times in patients with acute and chronic spinal cord lesions. Spinal Cord 2000;38:615-21. http://dx.doi.org/10.1038/ s.s. 3101066

5. Di Lorenzo C, Benninga MA. Pathophysiology of pediatric faecal incontinence. Gastroenterology 2004;126:S33-40. http://dx.doi.org/10.1053/i.gastro.2003.10.012

6. Glickman S, Kamm MA. Bowel dysfunction in spinal-cord-injury patients. Lancet 1996;347:1651-3. http://dx.doi.org/10.1016/S0140-6736(96)91487-7

7. Whitehead WE, Wald A, Norton NJ. Treatment options for fecal incontinence. Dis Colon Rectum 2001;44:131-73. http://dx.doi.org/10.1007/BF02234835
8. Vande Velde $S$, Van Bierliet $S$, Van Renterghem K, et al. Achieving fecal continence in patients with spina bifida: A descriptive cohort study. J Urol 2007;178:2640-4. http://dx.doi.org/10.1016/i. juro.2007.07.060

9. Pereira PL, Salvador OP, Arcas JA, et al. Transanal irrigation for the treatment of neuropathic bowel dysfunction. J Pediatr Urol 2010;6:134-8. http://dx.doi.org/10.1016/i.jpurol.2009.07.004

10. Malone PS, Ransley PG, Kiely EM. Preliminary report: The antegrade continence enema. Lancet 1990;336:1217-8. http://dx.doi.org/10.1016/0140-6736(90)92834-5

11. Malone PS, Curry II, Osborne A. The antegrade continence enema procedure why, when and how? World J Urol 1998;16:274-8. http://dx.doi.org/10.1007/s003450050066

12. Tiryaki S, Ergun 0, Celik A, et al. Success of Malone's antegrade continence enema (MACE) from the patients' perspective. Eur J Pediatr Surg 2010;20:405-12. http://dx.doi.org/10.1055/s-0030-1265156

13. Meurette $G$, Lehur $P A$, Coron E, et al. Long-term results of Malone's procedure with antegrade irrigation for severe chronic constipation. Gastroenterol Clin Biol 2010;34:209-21. http://dx.doi.org/10.1016/i. gcb.2009.12.009

14. Bani-Hani AH, Cain MP, Kaefer M, et al. The Malone antegrade continence enema: Single institutional review. J Urol 2008;180:1106-16. http://dx.doi.org/10.1016/i.juro.2008.05.062

15. Yerkes EB, Cain MP, King S, et al. The Malone antegrade continence enema procedure: Quality of life and family perspective. J Urol 2003;169:320-3. http://dx.doi.org/10.1016/S0022-5347(05)64116-X

16. Wedderburn A, Lee RS, Denny A, et al. Synchronous bladder reconstruction and antegrade continence enema. J Urol 2001;165:2392-5. http://dx.doi.org/10.1016/S0022-5347(05)66212-X

17. Neel KF. Total endoscopic and anal irrigation management approach to noncompliant neuropathic bladder in children: A good alternative. J Urol 2010;184:315-23. http://dx.doi.org/10.1016/i.juro.2010.01.058

18. Christensen $P$, Bazzocchi $G$, Coggrave $M$, et al. A randomized, controlled trial of transanal irrigation versus conservative bowel management in spinal cord-injured patients. Gastroenterology 2006;131:738-47. http://dx.doi.org/10.1053/i.gastro.2006.06.004

19. Del Popolo G, Mosiello G, Pilati C, et al. Treatment of neurogenic bowel dysfunction using transanal irrigation: A multicenter Italian study. Spinal Cord 2008;46:517-22. http://dx.doi.org/10.1038/ si.sc.3102167

20. Emmanuel A. Review of the efficacy and safety of transanal irrigation for neurogenic bowel dysfunction. Spinal Cord 2010;48:664-73. http://dx.doi.org/10.1038/sc.2010.5

21. Ausili E, Focarelli B, Tabacoo F, et al. Transanal irrigation in myelomeningocele children: An alternative, safe and valid approach for neurogenic constipation. Spinal Cord 2010;48:560-5. http://dx.doi. org $/ 10.1038 / s c .2009 .186$

22. Trbay $M$, Neel K. Management of neuropathic bowel dysfunction with transanal irrigation system. J Pediatr Urol 2010;6:S74-5. http://dx.doi.org/10.1016/i.purol.2010.02.139

23. Matsuno D, Yamazaki Y, Shiroyanagi Y, et al. The role of the retrograde colonic enema in children with spina bifida: Is it inferior to the antegrade continence enema? Pediatr Surg Int 2010;26:529-33. http:// dx.doi.org/10.1007/s00383-010-2585-6

Correspondence: Dr. Husain Alenezi, King Khalid University Hospital, King Saud University, Riyadh, Saudi Arabia; halenezi@hotmail.com 